\title{
Study of high-cycle rotating bending fatigue performance and fracture behavior in a pearlite-ferrite dual-phase steel
}

\author{
Xinbo $\mathrm{Ji}^{1}$, Sixin Zhao ${ }^{1}$, Liming $\mathrm{Fu}^{1}$, Jian Peng ${ }^{1}$, Jiaqiang $\mathrm{Gao}^{1}$, Dajiang $\mathrm{Yu}^{1}$, Zongze \\ Huang $^{1}$, and Aidang Shan ${ }^{1}$
}

${ }^{1}$ Affiliation not available

July 13, 2020

\begin{abstract}
To clarify the effects of ferrite morphologies and contents on high-cycle rotating bending fatigue property of pearlite-ferrite dual-phase (DP) steel used for fabrication of commercial vehicle crankshafts, two types of DP steels with different ferrite grain

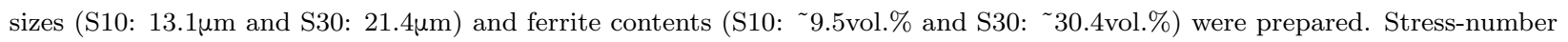
of high cycles to failure (S-N) fatigue of the two DP steels were evaluated. Experimental results showed a fatigue strength of $510 \mathrm{MPa}$ and $400 \mathrm{MPa}$ for S10 and S30 steels, respectively, at 107 cycles. Fatigue cracks in S10 steel extended preferentially along the grain boundary, but it was easy for crack propagation to extend within a pearlite colony to form a zigzag crack morphology. Crack roughness was enhanced and high stress was introduced to the crack surface due to this kind of crack propagation behavior, which has positive effects on slowing down crack propagation. However, the crack propagation in S30 steel mainly occurred inside the soft equiaxed coarse ferrite grain. Analysis revealed that little stress was introduced to the crack surface. These results show that it is possible to improve high cycle rotating bending fatigue strength of pearlite-ferrite DP steel by appropriately manipulating the volume fraction and microstructure morphology of ferrite phase.
\end{abstract}

\section{Hosted file}

Manuscript.docx available at https://authorea.com/users/341993/articles/469282-study-ofhigh-cycle-rotating-bending-fatigue-performance-and-fracture-behavior-in-a-pearliteferrite-dual-phase-steel

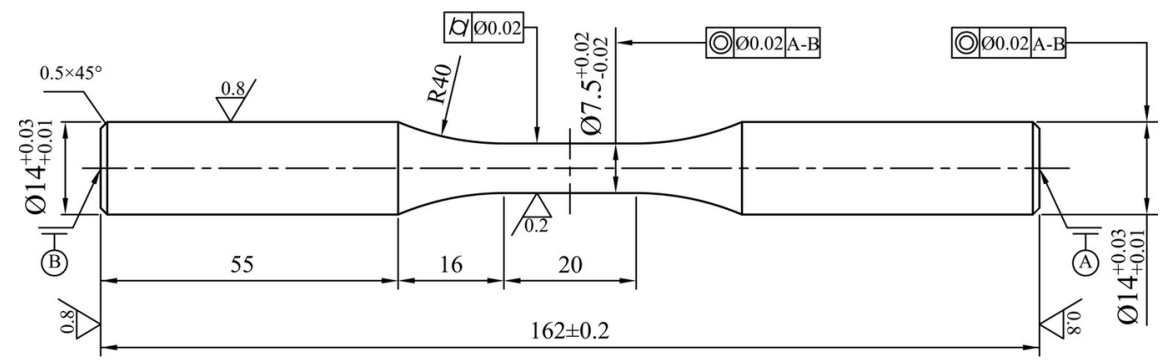



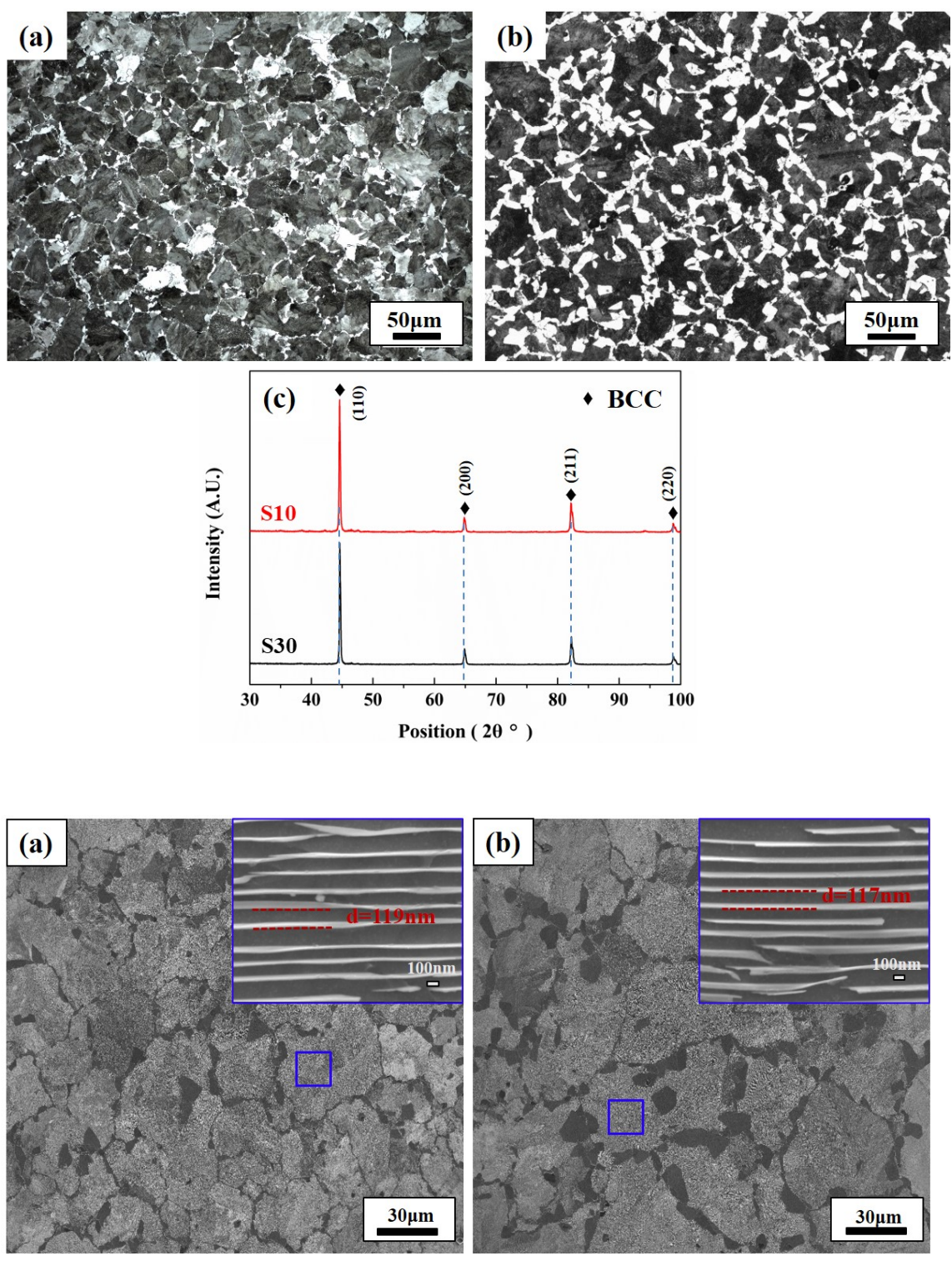

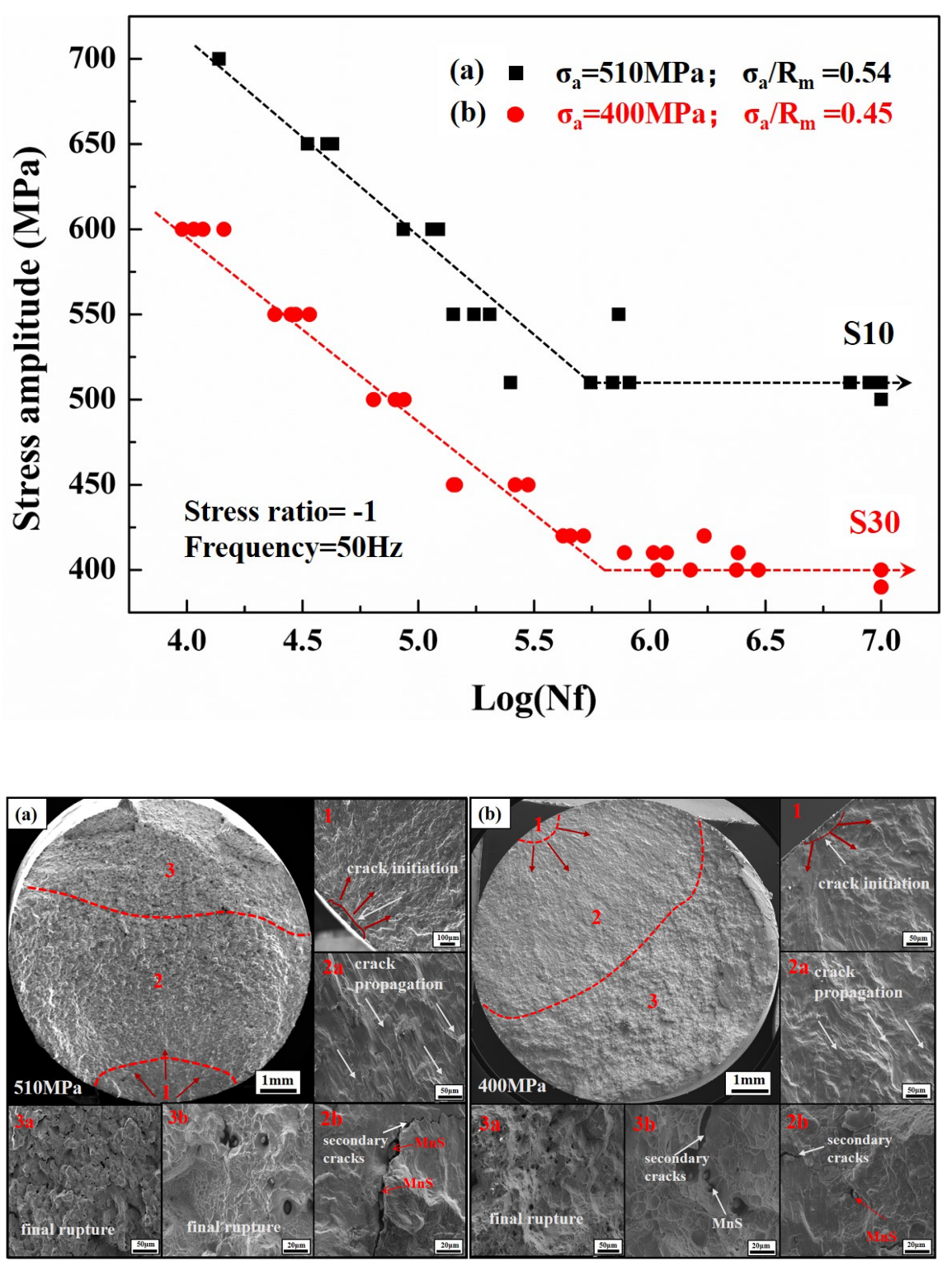

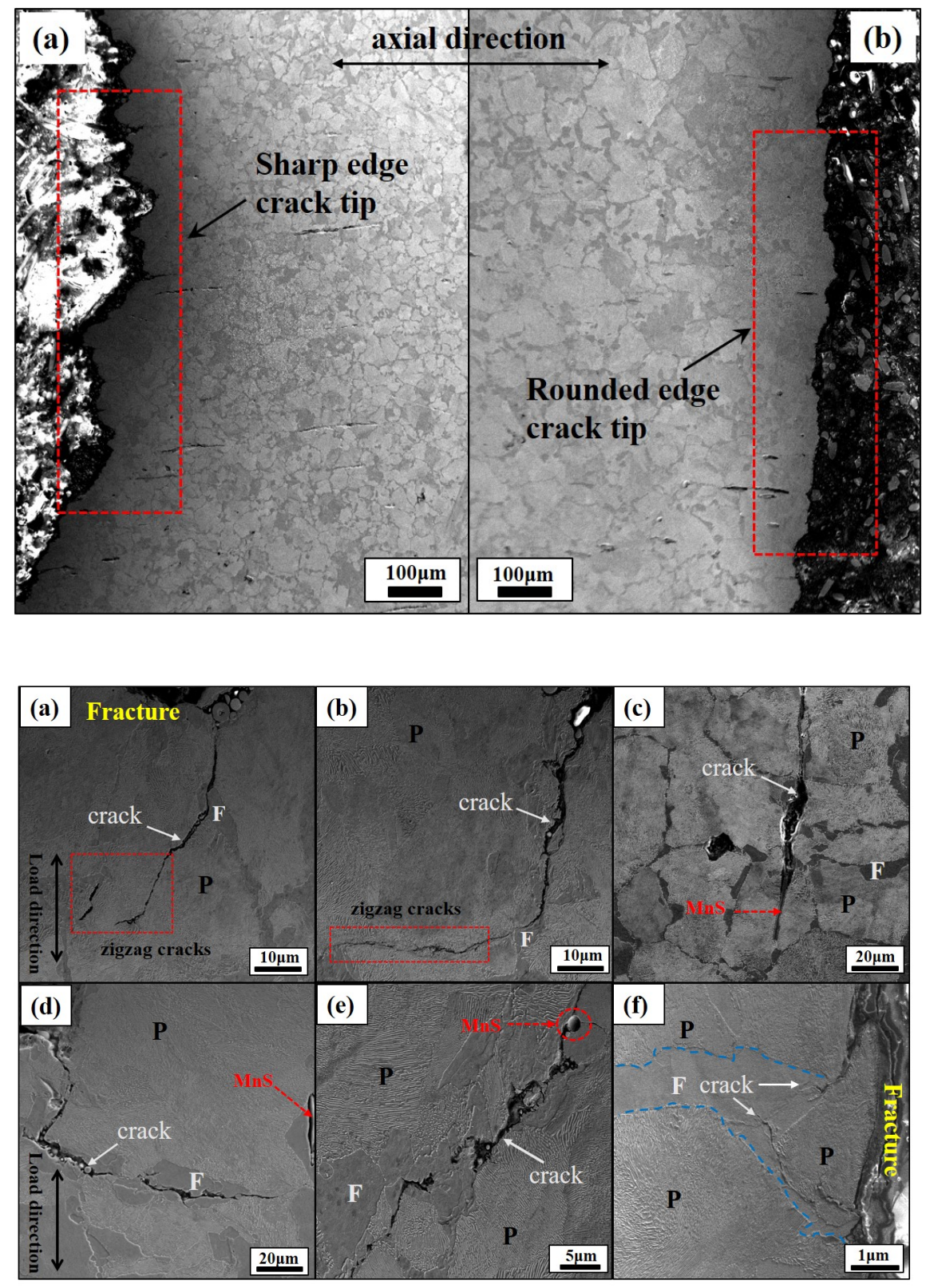


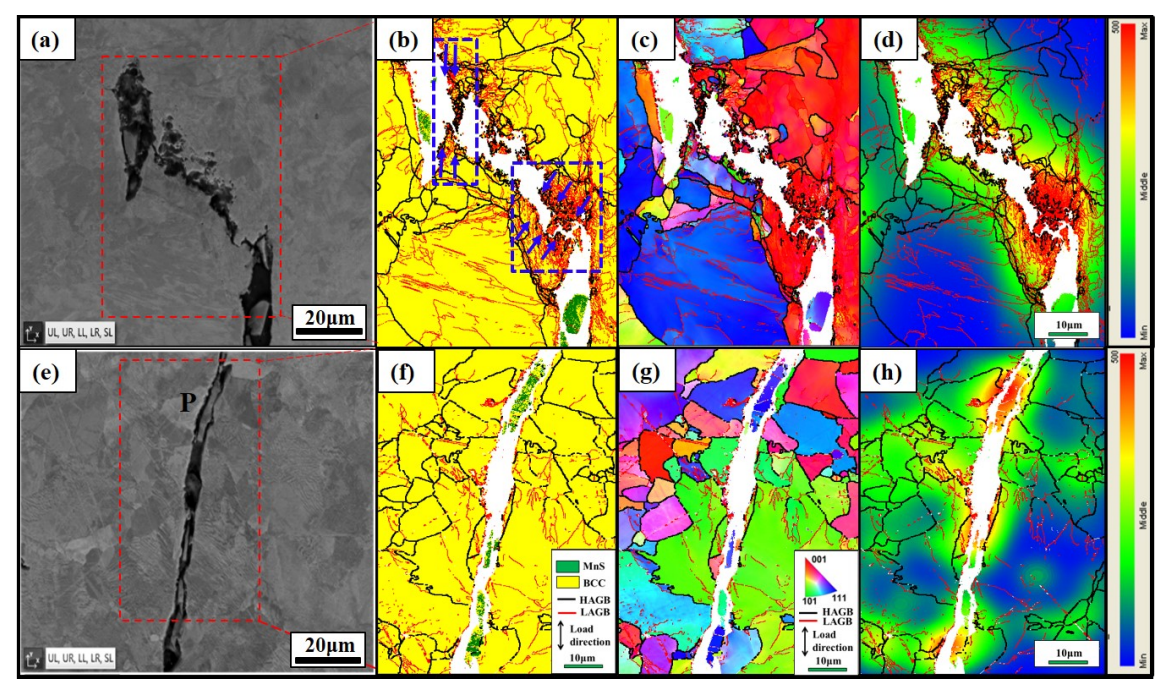

fracture appearance crack initiation crack propagation

(a)

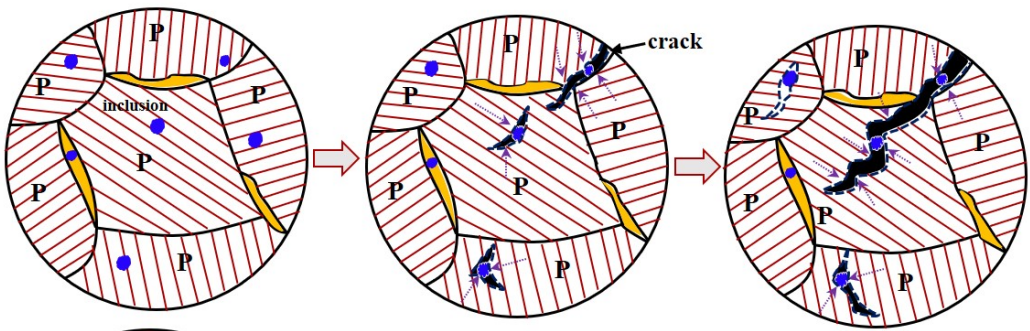

(b)

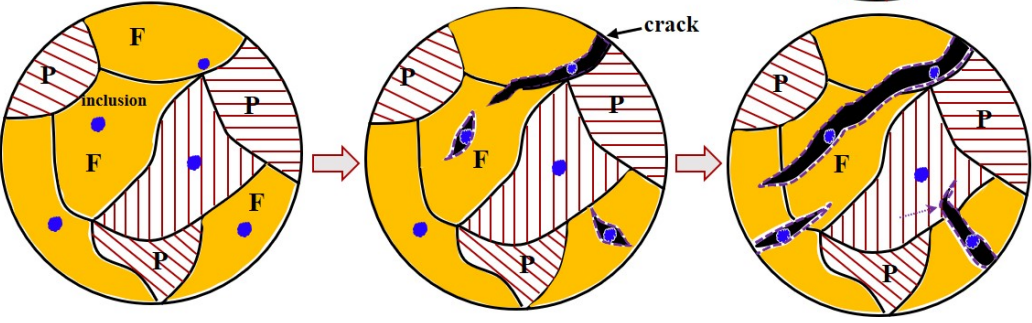

